\title{
Critical Appraisal of Traumatic Brain Injury and Its Management
}

\author{
Subhas Konar ${ }^{1}$ Orlin Pavlov ${ }^{2}$ Yeider Durango-Espinosa ${ }^{3}$ \\ Andrei Fernandes Joaquim ${ }^{4} \quad$ Amrita Ghosh ${ }^{5} \quad$ Ranabir Pal ${ }^{6}$

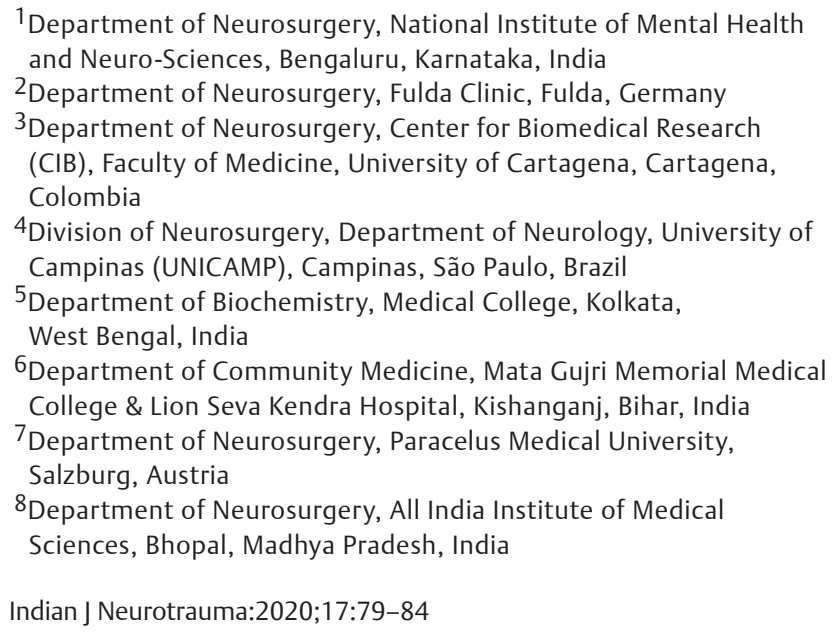

Ezequiel Garcia-Ballestas ${ }^{3}$

Luis Rafael Moscote-Salazar ${ }^{3,7}$ Amit Agrawal ${ }^{8}$

Address for correspondence Amit Agrawal, MD, MCh, Department of Neurosurgery, All India Institute of Medical Sciences, Saket Nagar, Bhopal 462020, Madhya Pradesh, India (e-mail: dramitagrawal@gmail.com).

\begin{abstract}
Critical appraisal of traumatic brain injury (TBI) management has always been marred with a conflict of differential approaches, with claims and counterclaims of outcomes among the research groups. We performed this study to review the management of TBI from risk factors to outcomes including the comorbidities and final clinical status. In conjunction with the aforesaid stabilization of TBI cases, prophylactic and definitive surgical approaches and other supporting interventions will ultimately decide the final outcomes in the long run. Improvements in the quality of care for patients with severe $\mathrm{TBI}$, with the reduction in mortality, have been demonstrated in high-income areas due to improvements in the health care system and not just in one isolated intervention. In the management of TBI, a fast and high index of suspicion is the key to success, from

Keywords

- trauma

- traumatic brain injury

- neurotrauma the initial assessment to the final rehabilitation of the cases, from the victim of risk factors to the victims of situation. The research groups feel that TBI prophylactic measures and primary care mitigation models are as important as definitive care, starting from prehospital care to dedicated care.
\end{abstract}

\section{Introduction}

Traumatic brain injury (TBI) has a devastating social and economic impact in the present society, mainly affecting the young population, with immediate complications and delayed sequel; yet, lately, the care of the TBI has received utmost interest. Road traffic accidents (45-60\%) tops the list of risk factors for the majority of TBIs followed by fall (20-30\%) and violence $(10 \%) .{ }^{1}$ The research groups have reported that in the majority of road traffic injury, the death and disabilities are mostly related to TBI and its sequel. ${ }^{2}$ Data on work-related
TBIs are sparse even from the developed countries where trauma care data are maintained. ${ }^{3}$ Trivial domestic injuries and domestic violence experienced in any age group have been associated with TBI followed by death and disability. Unfortunately, this remains an underreported segment in the whole world even in the developed countries. ${ }^{4}$ Furthermore, several factors related to resource and logistics management predict the outcome following the TBI., ${ }^{5,6}$ The most important predictive factors for survival of TBI is the space of time from injury event to primary care intervention starting from the primary survey, severity of primary injury, initial early 
ABCDE (airway, breathing, circulation, disability, exposure) support, specific management of airway, ventilation, and parenchymal injury.

\section{Where to Start from?}

All the trauma care should be started with a high index of suspicion of impending TBI and should have holistic approach of comprehensive health care with preventive, promotive, and curative components. TBI prevention should start with behavior change modification models to help people understand from early childhood "How they can save themselves at every steps of life from head crashes!" This initiation will hold hand of continuation of educational approach to prevent TBI by involving stakeholders and educationists. The undergraduate health care education should entail the basic management of TBI. All the levels of health care establishments should have adequate logistics of primary care of TBI with a well-oiled chain of referral for the optimum outcome of the TBI victims. In the initial phase, the framework of the dedicated infrastructure and logistics for the acute emergency situations paves the way for the tailor-made educational program for all shades and all levels of health care providers. ${ }^{7}$ This crystal-clear long-term capacity building program need to be initiated and implemented in the taxonomy of emergency neurologic life support $(\mathrm{ENLN})^{7}$ with a stepwise management from primary care of the whole spectrum of head crashes. The severe TBI with or without polytrauma and multifunction failure of victims has to be approached building from basic clinical competency to higher tiers of trauma expertise.

\section{Understanding of Pathophysiology}

The knowledge of the pathophysiology of TBI includes understanding the mechanisms involving the secondary injury and providing adequate management to break the cascade. Because of the complexity and diverse pathophysiology, TBI should be assessed including from biomechanical forces to very specific cellular changes at mitochondrial dysfunction. However, although it has been heavily studied, main mechanism that underlies the brain contusion is not yet fully clarified. ${ }^{8}$ In severe TBI, primary lesion results in skull fracture, cerebral contusion, and vascular and parenchymal injury, resulting in intracranial hemorrhage and augmentation in intracranial pressure (ICP). The inflammatory process, formation of edema, and excitotoxicity result in major ICP augmentation, which generates decline in cerebral perfusion pressure. While severity in primary lesion is the main determinant of outcome in patient with TBI, secondary lesions to cerebral tissue by physiological perturbations (secondary insults) contribute to worsening of outcomes. The critical secondary insults are hypotension (systolic blood pressure of $<90 \mathrm{~mm} \mathrm{Hg}$ in adult) and hypoxemia $\left(\mathrm{PaO}_{2}<60 \mathrm{~mm} \mathrm{Hg}\right)$. Other secondary insults include hypoglycemia, hyperglycemia, hypercapnia, hypocapnia, and increase in ICP. The pathophysiology of TBI is both engrossing and complex; many aspects of it have not yet been completely understood. For patients who survive initial trauma, the morbidity and mortality are greatly determined by the gravity of the lesion's secondary processes, which includes vascular and axonal damage, ischemia, and formation of cerebral edema. An intricate waterfall of changes in the molecular and functional levels occurs after the lesion. Several alterations are beneficial; however, many are detrimental.

\section{Clinical Examination and Clinical Classification of TBI}

After the securing airway, breathing, and circulation, a detailed neurologic examination is necessary. It includes an assessment of the Glasgow Coma Scale (GCS), pupils, and extraocular movements. Systemic examination is also equally important as it determines the outcome. The initial GCS score has a prognostic value in TBI. ${ }^{9}$ The severity in TBI is determined according to GCS, with minor TBI having a score of 13 to 15 , moderate having a score of 9 to 12 , and severe having a score of $<8 .{ }^{10}$ Additionally, TBI can be classified as focal damage, which transpires in a localized area and produces harm to underlying vessels and brain tissues besides the diffuse damage that extends throughout the entire brain. The diffuse type mainly implies axonal lesion, also called diffuse axonal lesion, cerebral edema, and hypoxia. TBI is a complex morbidity that should be understood as a public health issue attributable to high mortality and disability, and is one of the leading causes of death even in the developed countries. ${ }^{8}$ This condition encompasses an interesting spectrum that should not only consider its immediate consequences but also assess the long-term impact, especially those of working age. ${ }^{11}$ The classification of the severity of the TBI is based on the clinical status, using the $\mathrm{GCS},{ }^{10}$ knowing that a patient with mild TBI is (GCS 13-15), moderate (GCS 9-12), or severe (GCS $\leq 8$ ). ${ }^{10}$ Although it is not an exhaustive examination instrument, the GCS contributes together with other biological to frame the degree of injury product of the traumatic event factors, thereby providing diagnostic and prognostic information. ${ }^{12}$ Also, according to the radiological characteristics of the lesion in the computed tomography (CT) or magnetic resonance imaging (MRI), they can be classified into brain focal injuries or diffuse injury (affecting multiple brain regions)..$^{13}$ In spite of being a very simple concept, excluding the possibility that from the most severe to the most moderate of the ways of damage, they may occur with focal and diffuse combinations; categorizing them helps to frame key ideas about brain injuries. ${ }^{12}$ The documentation of the extracranial injury is also as important as cranial. The TBI outcomes differ in patients with extensive extracranial injuries than in those without the injuries.

\section{Concepts in the Management}

The basic concepts in the management of injuries are management of airway and bleeding. This mandate essential service have also been stressed through the health care 
delivery system in the low- and middle-income countries as a human rights approach. ${ }^{14}$ Prehospital trauma care is the most cost-effective approach in the TBI management if we can involve lay first responders who effectively retain and confidently apply their knowledge on ground situation. ${ }^{15}$ In the low- and middle-income countries, $80 \%$ of injury deaths occur in the prehospital setting in the absence of well-drilled emergency management systems. ${ }^{16}$ Prehospital health care must be strengthened by the first responder training program on the $A B C D E$ module that has the potential to drastically reduce unnecessary morbidity and mortality on the roads. ${ }^{17}$ The medical management starts with primary care of airway, breathing, and circulation followed by specific treatment to prevent secondary brain injury. ${ }^{18}$ The surgical management of specific brain injuries such as an extradural dural hematoma, subdural hematoma, parenchymal lesion, and depressed cranial fractures depends on proper indication and timing of intervention ( - Table 1) ${ }^{19,20}$ In basic sense, the treatment is guided to prevent progression of the lesion, reduce edema, control ICP, and maintain good brain perfusion, ${ }^{8,21}$ and to reduce mortality and improve outcomes. ${ }^{22-24}$

\section{Investigation}

Noninvasive investigations such as neuroimaging with CT scan (due to its availability, cost, and sensitivity for acute intracranial hemorrhage and fractures) are the imaging modality of choice. ${ }^{25,26}$ However, in recent decades, MRI has been increasingly being used as it offers improved soft tissue imaging with higher sensitivity to detect wider varieties of traumatic pathologies viz. diffuse axonal injury. ${ }^{27}$ MRI is not helpful in the acute stage of TBI but in few conditions

Table 1 Neurotrauma surgical check list

\begin{tabular}{|c|c|c|c|}
\hline & Item & Verified & Not verified \\
\hline 1. & Patient details & & \\
\hline 2. & Checking the indications & & \\
\hline 3. & Biochemical parameters including the coagulation profile & & \\
\hline 4. & Imaging preparation & & \\
\hline 5. & Extent of craniectomy (hemicraniectomy/bilateral) & & \\
\hline 6. & Dural substitute/sealant material & & \\
\hline 7. & Anesthesia & & \\
\hline 8. & $\begin{array}{l}\text { Delimit caution areas } \\
\text { Superior sagittal sinus } \\
\text { Transverse sinus } \\
\text { Venous lakes }\end{array}$ & & \\
\hline 9. & $\begin{array}{l}\text { Select head holder: } \\
\text { Horseshoe } \\
\text { head fixation }\end{array}$ & & \\
\hline 10. & $\begin{array}{l}\text { Draw Incision } \\
\text { L.G. Kempe modified incision } \\
\text { Large reverse question mark frontotemporoparietal incision } \\
\text { Kjellberg type }\end{array}$ & & \\
\hline 11. & Asepsis and antisepsis & & \\
\hline 12. & Perform incision & & \\
\hline 13. & Scalp hemostasis & & \\
\hline 14. & Burr holes & & \\
\hline 15. & Paranasal sinus damage control & & \\
\hline 16. & Durotomy & & \\
\hline 17. & Dural hemostasis & & \\
\hline 18. & Inspect and correct & & \\
\hline 19. & Dural substitute & & \\
\hline 20. & Drainage & & \\
\hline 21. & $\begin{array}{l}\text { Bone flap } \\
\text { Discard } \\
\text { Abdominal subcutaneous pocket } \\
\text { Cryopreservation }\end{array}$ & & \\
\hline
\end{tabular}


such as diffuse axonal injury or brain stem injury, it is superior to CT scan. It better delineates the extent of damage and progression of damage. It is also helpful in monitoring the stages of recovery. ${ }^{28}$ Advanced MRI (diffusion tensor imaging or resting stage) in the chronic phase also helps understand the amount of white matter loss and the concept of cortical reorganization. The invasive methods have higher expected complications compared with the noninvasive techniques, yet need to be employed in TBI care. ${ }^{29}$ Invasive real-time multimodal neurologic monitoring measure, track, and detect the pathophysiological processes of the TBI patients on perfusion, oxygenation, cellular metabolism, ICP, and electrical activities. These guide the ongoing medical interventions for optimum functional neurologic outcomes, yet these are under scrutiny to become "gold standards" in the standard office procedures..$^{30,31}$

\section{After Hospital Discharge}

The research groups have evaluated the predictors of morbidity/mortality in emergency hospital care settings and increased survival after TBI cases. This has attracted attention on continuity of care regarding discharge destinations from acute care settings led to burdening spaces with long-lasting disabilities as per clinical priorities. Ultimately, after discharge from hospital, TBI cases get domiciliary care in the community settings with limited cognitive, behavioral, and physical functions for optimum medical, social, vocational, and psychological rehabilitations. ${ }^{32}$ Neuropsychological evaluation is required in all patients to determine the rehabilitation process and classify the severity of the sequels. In this way, institutions that manage patients with brain injuries should incorporate neuropsychologists who can create rehabilitation strategies based on their own ecologies. ${ }^{33}$

\section{Prevention}

It is worrisome that despite the implementation of educational strategies focused on the prevention of non-accidental trauma (NAT) and implementation of improved prevention programs, there is increase in cases of cranial injuries. ${ }^{34}$ Abusive head trauma is a serious problem, with some type of permanent neurologic injury as high as $60 \%$ of the cases..$^{35}$ This emphasizes the need to develop prevention strategies as an urgent effort. ${ }^{36}$ It is widely known that abusive head trauma is an issue of global concern, and hence while developing preventive strategies, we need to consider few relevant points including the following: (1) prevention strategies should consider cultural and educational levels, (2) emphasis should be made on strengthening prevention strategies including active segmentation of the cases, (3) implementation cost should include home visits to specific populations, and (4) the development and adherence to clinical guidelines. In the imaging evaluation, even though tomography is the routine method in the evaluation of cranial neurotrauma, we suggest that the performance of brain MRI shall further help identify the lesions such as subdural hematomas. The authors very well highlight the role of infant crying, which can be used by parents as well as clinicians to identify the children at risk without any cost involved. Similarly, other clinical characteristics such as bruises and other external signs of injuries can be shortlisted and a health education program can be proposed to create awareness in the community. The use of focused ultrasound at the accident spot is an effective tool to triage the TBI patients and refer the respective cases to the tertiary hospital.

\section{Future Research}

The research practice is an integral part of altruism in the health care delivery system. The translational researches in neurotrauma should try to internalize and integrate better data documentation in resource poor health systems, improve capacities for dedicated referral hospitals and capacity building and subspecialty training that is still in the development process. TBI prevention is based on two empathetic pillars of futuristic vision and proactivity, which range from hazards recognition to initiation and continuation of surveillance including mitigation, planning, registry, and intervention programs with concurrent holistic evaluation. ${ }^{37-42}$ Furthermore, pointof-care injury biomarkers need to be part of research and development of clinical practice guidelines in day-to-day TBI care with associated injuries. ${ }^{43}$ An interprofessional research team approach involving TBI patients and their caregivers can help us conduct translational research, from reduction of risk factors to optimizing outcomes. ${ }^{44,45}$

\section{Conclusion}

TBI is a major public health burden globally as well as in India, posing an acute emergency, and its management should include a quick assessment and specific treatment by dedicated persons with dedicated infrastructures and optimal logistics. Furthermore, global data on occupational trauma are not freely available due to underreporting, limited reporting, and compensation schemes; nonharmonized data on accident and notification systems lead to shrinkage of true information. The goal of treatment of TBI is the critical control of the ICP and cerebral oxygenation, which have been accepted as clinical variables of outcome parameters. The prevention efforts should get priorities from where the highest TBI and/or highest hazards have been reported. Furthermore, other associated issues from prevention and prophylactic approaches injuries to definitive care at the right time, at the right place, and by the right person with right infrastructure and right logistics embedded in a right systems approach can only solve this colossal global public health problem.

\section{Conflict of Interest}

None declared.

\section{References}

1 Agrawal A. A critical appraisal of neurotrauma and neurocritical care perspectives of traumatic brain injuries in Indian scenario. Indian J Neurotrauma 2013;10(1):38-42 
2 Pal R, Agarwal A, Galwankar S, et al. The 2014 Academic College of Emergency Experts in India's INDO-US Joint Working Group (JWG) White Paper on "Developing Trauma Sciences and Injury Care in India." Int J Crit Illn Inj Sci 2014;4(2):114-130

3 Konda S, Reichard A, Tiesman HM, Hendricks S. Non-fatal work-related traumatic brain injuries treated in US hospital emergency departments, 1998-2007. Inj Prev 2015;21(2): $115-120$

4 Mckee AC, Daneshvar DH. The neuropathology of traumatic brain injury. Handb Clin Neurol 2015;127:45-66

5 Tripathi M, Shukla D. Intensive care management of severe traumatic brain injury in India. J Neurosci Rural Pract 2016;7(4):481-482

6 Shukla D, Devi BI, Agrawal A. Outcome measures for traumatic brain injury. Clin Neurol Neurosurg 2011;113(6):435-441

7 Miller CM, Pineda J, Corry M, Brophy G, Smith WS. Emergency neurologic life support (ENLS): evolution of management in the first hour of a neurological emergency. Neurocrit Care 2015;23(Suppl 2):S1-S4

8 Alvis-Miranda H, Alcala-Cerra G, Moscote-Salazar LR. Traumatic cerebral contusion. Romanian Neurosurg; 2013; XX 2 125-137. Doi: 10.2478/romneu-2013-0001. Retrieved from: http://archive.sciendo.com/ROMNEU/romneu.2013.20.issue-2/ romneu-2013-0001/romneu-2013-0001.pdf. Accessed May 30, 2020

9 Saika A, Bansal S, Philip M, Devi BI, Shukla DP. Prognostic value of FOUR and GCS scores in determining mortality in patients with traumatic brain injury. Acta Neurochir (Wien) 2015;157(8):1323-1328

10 Teasdale G, Jennett B. Assessment of coma and impaired consciousness. A practical scale. Lancet 1974;2(7872):81-84

11 Davanzo JR, Sieg EP, Timmons SD. Management of traumatic brain injury. Surg Clin North Am 2017;97(6):1237-1253

12 McGinn MJ, Povlishock JT. Pathophysiology of traumatic brain injury. Neurosurg Clin N Am 2016;27(4):397-407

13 Pervez M, Kitagawa RS, Chang TR. Definition of traumatic brain injury, neurosurgery, trauma orthopedics, neuroimaging, psychology, and psychiatry in mild traumatic brain injury. Neuroimaging Clin N Am 2018;28(1):1-13

14 Mock C,, Lormand J, Goosen J, Joshipura M, Peden M. Guidelines for Essential Trauma Care. Geneva: World Health Organization; 2004

15 Jayaraman S, Mabweijano JR, Lipnick MS, et al. First things first: effectiveness and scalability of a basic prehospital trauma care program for lay first-responders in Kampala, Uganda. PLoS One 2009;4(9):e6955

16 Mock CN, Jurkovich GJ, nii-Amon-Kotei D, Arreola-Risa C, Maier RV. Trauma mortality patterns in three nations at different economic levels: implications for global trauma system development. J Trauma 1998;44(5):804-812, discussion 812-814

17 Vyas D, Hollis M, Abraham R, et al. Prehospital care training in a rapidly developing economy: a multi-institutional study. J Surg Res 2016;203(1):22-27

18 Muizelaar JP, Lutz HA III, Becker DP. Effect of mannitol on ICP and $\mathrm{CBF}$ and correlation with pressure autoregulation in severely head-injured patients. J Neurosurg 1984;61(4):700-706

19 Shima K, Aruga T, Onuma T, Shigemori M; members of the Japanese Guidelines Committee on the Management of Severe Head Injury (2nd Edition), and the Japan Society of Neurotraumatology. JSNT-guidelines for the management of severe head injury (abridged edition) Asian J Neurosurg 2010;5(1):15-23

20 Bratton SL, Chestnut RM, Ghajar J, et al. Brain Trauma Foundation; American Association of Neurological Surgeons; Congress of Neurological Surgeons; Joint Section on Neurotrauma and Critical Care, AANS/CNS. Guidelines for the management of severe traumatic brain injury. VIII Intracranial pressure. J Neurotrauma 2007;24(Suppl 1):S255-S258

21 Ahmad Helmy AK, Salmah Jalaluddin WM, Ab Rahman IG. Computed tomography perfusion imaging on traumatic cerebral contusion: a preliminary report. Malays J Med Sci 2010;17(4):51-56

22 Carney N, Totten AM, O'Reilly C, et al. Guidelines for the management of severe traumatic brain injury, fourth edition. Neurosurgery 2017;80(1):6-15

23 Dash $\mathrm{HH}$, Chavali S. Management of traumatic brain injury patients. Korean J Anesthesiol 2018;71(1):12-21

24 Geeraerts T, Velly L, Abdennour L, et al; French Society of Anaesthesia; Intensive Care Medicine; in partnership with Association de neuro-anesthésie-réanimation de langue française (Anarlf); French Society of Emergency Medicine (Société Française de Médecine d'urgence (SFMU); Société française de neurochirurgie (SFN); Groupe francophone de réanimation et d'urgences pédiatriques (GFRUP); Association des anesthésistes-réanimateurs pédiatriques d'expression française (Adarpef). Management of severe traumatic brain injury (first 24 hours) Anaesth Crit Care Pain Med 2018;37(2):171-186

25 Agarwal R, Bergey M, Sonnad S, Butowsky H, Bhargavan M, Bleshman $\mathrm{MH}$. Inpatient $\mathrm{CT}$ and MRI utilization: trends in the academic hospital setting. J Am Coll Radiol 2010;7(12): 949-955

26 Kumar A, Reddy U, Pratyusha V, et al. Commonly available CT characteristics and prediction of outcome in traumatic brain injury patients. Romanian Neurosurg 2017:101-110

27 Altmeyer W, Steven A, Gutierrez J. Use of magnetic resonance in the evaluation of cranial trauma. Magn Reson Imaging Clin N Am 2016;24(2):305-323

28 Wintermark M, Sanelli PC, Anzai Y, Tsiouris AJ, Whitlow CT; American College of Radiology Head Injury Institute. Imaging evidence and recommendations for traumatic brain injury: advanced neuro- and neurovascular imaging techniques. AJNR Am J Neuroradiol 2015;36(2):E1-E11

29 Raboel PH, Bartek J Jr, Andresen M, Bellander BM, Romner B. Intracranial pressure monitoring: invasive versus non-invasive methods-a review. Crit Care Res Pract 2012;2012:950393

30 Stocchetti N, Le Roux P, Vespa P, et al. Clinical review: neuromonitoring - an update. Crit Care 2013;17(1):201

31 Lazaridis C, Robertson CS. the role of multimodal invasive monitoring in acute traumatic brain injury. Neurosurg Clin $\mathrm{N}$ Am 2016;27(4):509-517

32 Zarshenas S, Colantonio A, Alavinia SM, Jaglal S, Tam L, Cullen $\mathrm{N}$. Predictors of discharge destination from acute care in patients with traumatic brain injury: a systematic review. J Head Trauma Rehabil 2019;34(1):52-64

33 Said PZH, Ghosh A, Pal R, Poli N, Moscote-Salazar LR, Agrawal A. Impact of traumatic brain injury on cognitive functions. Arch Ment Health 2018;19:97

34 Thompson LW, Bass KD, Agyei JO, et al. Incidence of nonaccidental head trauma in infants: a call to revisit prevention strategies. J Neurosurg Pediatr 2019 (e-pub ahead of print) Doi:10.3171/2019.7.PEDS195

35 Case ME, Graham MA, Handy TC, Jentzen JM, Monteleone JA; National Association of Medical Examiners Ad Hoc Committee on Shaken Baby Syndrome. Position paper on fatal abusive head injuries in infants and young children. Am J Forensic Med Pathol 2001;22(2):112-122

36 Hoz S, Moscote-Salazar LR. Prevention of neurotrauma: an evolving matter. J Neurosci Rural Pract 2017;8(Suppl 1): S141-S143

37 Agrawal A, Savardekar A, Singh M, et al. Pattern of reporting and practices for the management of traumatic brain injury: an overview of published literature from India. Neurol India 2018;66(4):976-1002 
38 Pal R. Traumatic brain injury registry: Need of the hour. J Neurosci Rural Pract 2016;7(4):483-484

39 Alothman MH, Tamer WA, Moscote-Salazar LR, Ghosh A, Pal R, Agrawal A. Challenges and opportunities in reporting trauma-related research: a case study from Syria. Indian J Neurotrauma 2019;16:91-93

40 Singh M, Pal R, Yarasani P, Bhandarkar P, Munivenkatappa A, Agrawal A. International Classification of Diseases-based audit of the Injury Database to understand the injury distribution in patients who have sustained a head injury (International Classification of Diseases Codes: S00-S09). J Emerg Trauma Shock 2018;11(4):253-264

41 Pal R, Munivenkatappa A, Agrawal A, et al. Predicting outcome in traumatic brain injury: sharing experience of pilot traumatic brain injury registry. Int J Crit Illn Inj Sci 2016;6(3):127-132
42 Agrawal A, Munivenkatappa A, Pal R, et al. Traumatic Brain Injury Registry: sharing the pilot study experience to foster a multicenter project on traumatic brain injury core data. Indian J Neurotrauma 2016;13(2):81-87

43 Quinones-Ossa G, Padilla-Zambrano H, Pal R, et al. Biomarkers in acute brain trauma: a narrative review. J Acute Dis 2019;8:1-6

44 Agrawal A, Munivenkatappa A, Shukla DP, et al. Traumatic brain injury related research in India: an overview of published literature. Int J Crit Illn Inj Sci 2016;6(2):65-69

$45 \mathrm{Pal}$ R. Interprofessional research team approach is the key to traumatic brain injury intervention. J Neurosci Rural Pract 2020;11(1):3-4 